\title{
Article \\ Sources of Meaningful Work for Blue-Collar Workers
}

\author{
Tiina Saari *, Minna Leinonen (D) and Katriina Tapanila \\ Faculty of Social Sciences, Tampere University, 33014 Tampere, Finland; minna.leinonen@tuni.fi (M.L.); \\ katriina.tapanila@tuni.fi (K.T.) \\ * Correspondence: tiina.saari@tuni.fi
}

check for updates

Citation: Saari, Tiina, Minna Leinonen, and Katriina Tapanila. 2022. Sources of Meaningful Work for Blue-Collar Workers. Social Sciences 11: 2. https://doi.org/10.3390/ socsci11010002

Academic Editors: Markus Hertwig and Nigel Parton

Received: 27 September 2021

Accepted: 14 December 2021

Published: 22 December 2021

Publisher's Note: MDPI stays neutral with regard to jurisdictional claims in published maps and institutional affiliations.

Copyright: (C) 2021 by the authors. Licensee MDPI, Basel, Switzerland. This article is an open access article distributed under the terms and conditions of the Creative Commons Attribution (CC BY) license (https:// creativecommons.org/licenses/by/ $4.0 /)$.

\begin{abstract}
Research on the meaningfulness of work has increased in recent years, yet there is a limited body of qualitative studies on the topic. This article analyzes how the four basic psychological needs, namely autonomy, competence, relatedness, and beneficence, are articulated as sources of meaningful work by blue-collar workers. The research data consist of responses $(N=679)$ to one open-ended question in a survey and semi-structured interviews $(N=29)$ with blue-collar workers from property services and the manufacturing industry in Finland. The data were analyzed by theory-driven content analysis. The main findings are: first, autonomy, competence, relatedness, and beneficence appear as sources of meaningfulness in blue-collar work. Second, blue-collar workers see their work as autonomous and requiring diverse competences. Relatedness in blue-collar work entails having good relations with co-workers and striving to maintain those relationships. Beneficence is multilevel: helping clients, co-workers, organization and even the whole society through work. Organizations should develop organizational practices that may enhance the meaningfulness of work, such as opportunities to use and develop occupational skills. This article participates in the discussion about how satisfying these four basic psychological needs can be a source of meaningful work and offers a sociological-contextual perspective on the discussion about meaningfulness of work.
\end{abstract}

Keywords: blue-collar work; meaningfulness of work; self-determination theory

\section{Introduction}

Research on the meaningfulness of work has increased in recent years (e.g., LipsWiersma et al. 2016; Martela and Riekki 2018; Nikolova and Cnossen 2020). Some scholars would even elevate meaningful work to the status of a fundamental human need, which all people require in order to satisfy their inherent interests in freedom, autonomy, and dignity (Yeoman 2014). This study concentrates on meaningfulness in blue-collar work. Blue-collar work may not be the first to come to mind when thinking about meaningful work, because it is often seen only as dirty, physically demanding, low skilled, and low paid (Torlina 2011). However, there are already some studies which have revealed that manual work can be meaningful for workers (Lips-Wiersma et al. 2016; Wrzesniewski and Dutton 2001; Kreiner et al. 2006; Isaksen 2000). It is important to study blue-collar workers and the meaningfulness of their work, because even though knowledge work has become more common, blue-collar workers still make up a large part of the workforce in Europe and Finland (Statistics Finland 2021; Eurofound 2017). In addition, many bluecollar occupations have been named "essential work" during the COVID-19 pandemic (e.g., Milligan et al. 2021).

Self-determination theory (SDT) is one of the most used theories when analyzing the meaningfulness of life and work (Ryan and Deci 2000, 2017). Numerous studies (e.g., Allan et al. 2016; Ryan and Deci 2000, 2017; Autin and Allan 2020; Nikolova and Cnossen 2020) present the three basic psychological needs, namely autonomy (i.e., a sense of volition), competence (i.e., the ability to use one's skills and capabilities), and relatedness (i.e., a sense of social belonging) as sources or predictors of meaningfulness of work. In their extensive meta-analytic review of the SDT conceptualization of basic psychological needs 
and the empirical support for the theory, Van den Broeck et al. (2016) concluded that the needs for autonomy, competence and relatedness mostly meet the criteria proposed for what basic psychological needs represent. However, Martela and Riekki (2018) suggested that, in addition to these three, beneficence, referring to the sense of making a positive contribution, is also such a basic psychological need that it should be noted as a major predictor of meaningfulness of work.

Satisfying the four basic psychological needs has been found to have independent effects on experiencing work as meaningful (Martela and Riekki 2018). In this study, all the four forementioned needs are analyzed from the viewpoint of whether they appear in our qualitative research data, and how. We ask how satisfying the basic psychological needs is articulated as sources of meaningful work in interviews with blue-collar workers' and in their responses to the open-ended question of the survey.

Although the meaningfulness of work has been much studied in recent years, there are fewer qualitative studies on the subject and even fewer on blue-collar work. However, there are some qualitative studies (Isaksen 2000; Secrest et al. 2005; Scarduzio et al. 2018) and also mixed-methods studies (Bunderson and Thompson 2009; Weeks and Schaffert 2019) on the meaningfulness of work. Thus, the present study makes three distinct contributions: first, it studies rarely investigated blue-collar workers and their experiences of meaningful work. Second, it participates in the discussion about how satisfying these four basic psychological needs, namely autonomy, competence, and relatedness, accompanied by beneficence, can be a source of meaningful work and offers a sociological-contextual perspective on them. Third, it adds to the limited body of qualitative studies on the meaningfulness of work.

\section{Meaningfulness of Work and Sources of Meaningful Work}

Although the interest in meaningfulness of work has grown in the 21st century, the roots of the debate are longer. Hackman and Oldham (1976) introduced the job characteristics model, stating that three core characteristics, namely skill variety, task significance, and task identity preceded the experience of meaningfulness in work. They saw meaningfulness as a subjective experience, and according to them it describes "the degree to which the employee experiences the job as one which is generally meaningful, valuable, and worthwhile" (Hackman and Oldham 1976, p. 256).

Since Hackman and Oldham, meaningfulness of work has been defined in many ways. For example, it has been described as a subjective experience of how significant and intrinsically valuable people find their work to be (Martela and Riekki 2018) and how positive a meaning it holds for them (Rosso et al. 2010). Pratt and Ashforth (2003) defined meaningful work as work which is purposeful and significant, and Steger et al. (2012) highlighted its growth- and purpose-oriented rather than pleasure-oriented focus. BothNwabuwe et al. (2017) found altogether 14 different definitions and identified four different categories of meaningful work: positive significance and/or purpose, constituents of meaningful work, fit perspective and fulfillment. In accordance with the definitions above, we define the meaningfulness of work as an employee's subjective experience that the work itself is valuable for him/her, and not merely a way to earn money or to achieve some other instrumental goals.

Scholars have suggested different sources of or pathways to meaningfulness of work. For instance, Lips-Wiersma and Morris (2009) highlight the importance of developing and becoming self, creating unity with others, serving others, and expressing full potential as sources of meaningful work and life. Developing and becoming self refers to moral development, personal growth, and the ability to stay true to oneself. In addition, creating unity with others means an ability to share values, belong to a group, and work together. Moreover, serving others refers to the ability to make a difference within the organization or to see a connection between one's work and a transcendent cause, usually in addressing social, economic or environmental problems. Finally, expressing full potential refers to situations where achieving is meaningful through the act of mastering something and the individual is able to create and influence the work. Developing and becoming self and 
expressing full potential are related to the individual, i.e., the 'self', whereas unity with others and serving others are connected with the work community or to society, i.e., 'others' (Lips-Wiersma and Morris 2009, pp. 501-2).

Based on a literature review of the meaningfulness of work, Rosso et al. (2010) have outlined four main pathways to meaningful work. These pathways resonate largely with the sources of meaningful work defined by Lips-Wiersma and Morris (2009). Self-connection refers to acting in concordance with one's identity and authentic self. Unification means belongingness and actions bringing individuals into harmony with each other. Contribution, in turn, refers to serving something greater than the self and, finally, individuation, stands for actions that define individuals as competent, autonomous and valuable. In 'self-connection' and 'individuation', the activity is directed towards the self, whereas in 'unification' and 'contribution' it is targeted towards others (Rosso et al. 2010, pp. 113-5).

Chalofsky (2003), in turn, offers a more holistic and individualistic viewpoint on the sources of meaningful work, focusing on the interplay between individual and work in the individual's life context. Based on a literature review, he found that sense of self, the work itself, and a sense of balance form an integrated whole. An individual's ability to experience meaningfulness in work depends on his or her values and their compatibility with the values of the work as well as his or her commitment to that work. The working environment frames the work by offering autonomy, enhancing learning, and giving the opportunity to fulfill one's purpose through work. Sense of balance is about balancing the work self and the personal self as well as work and other areas of life (Chalofsky 2003). In Chalofsky's theorization, the work community and societal impact of the work are not taken into account. Instead, the organizational and managerial aspects are seen as essential in fostering meaningfulness of work.

The sources of meaningfulness named in the research literature referred to above include both individual and contextual elements. In this research, we focus mainly on the contextual elements of the sources of meaningful work, such as belonging to a group, being able to learn and work autonomously and making a difference in an organization or in society as a whole. We assume that they are relevant especially in blue-collar work, where the opportunities to exert influence in work are seen as limited (see also Lips-Wiersma et al. 2016) and thus bound to organizational structures and preconditions of work.

\section{Self-Determination Theory and Meaningfulness of Work}

Many studies present the psychological needs included in Ryan and Deci's (2000, 2017) self-determination theory (SDT) as sources or predictors of meaningfulness of work. The SDT comprises three psychological needs people have: autonomy, competence, and relatedness.

In the SDT literature, autonomy refers to individuals' need to act with a sense of ownership of their behavior and to feel psychologically free (Deci and Ryan 2000; Ryan and Deci 2017). However, autonomy refers to the need to act with a sense of choice, even when doing so means following the wishes of others (Trougakos et al. 2013).

Competence implies a need to feel a sense of mastery and efficacy in one's activities. It is about feeling able and capable to do the work or tasks required, and to be able to accomplish projects and achieve goals. Competence also includes developing new skills (Deci and Ryan 2000; Ryan and Deci 2017). Competence as a basic need originally became a focus of SDT research as researchers analyzed how and why verbal praise, which is extrinsic in nature, enhances intrinsic motivation (Deci et al. 1999). Thus, supervisors hold an important key to enhancing meaningfulness of work, namely feedback and support for their employees (Frémeaux and Pavageau 2020).

Relatedness refers to the need to feel connected to at least some others, to have caring relationships, and belong to a community. This need is satisfied when people see themselves as members of a group, experience a sense of communion, and develop close relations (Deci and Ryan 2000; Ryan and Deci 2017). 
Martela and Riekki (2018) suggest that there are not only three but four psychological needs and satisfying them can substantially influence meaningfulness of work. In addition to autonomy, competence, and relatedness, there is also beneficence. The need for beneficence refers to the sense of making a positive contribution or having a prosocial impact. Thus, beneficence means doing something to benefit other people rather than oneself (Martela and Riekki 2018). According to Martela and Riekki's results, all four needs are associated with meaningful work. As an important notion for our study, they also found that the same basic needs seemed to be relevant in both higher and lower occupational positions. In this study, we analyze not only the three basic psychological needs, but also include beneficence in the analysis as the fourth need. Thereby, we will contribute to the discussion about including beneficence as one of the basic needs.

When comparing these four psychological needs as sources of meaningfulness to the results of Lips-Wiersma and Morris (2009) introduced above, there are some similarities. In the study by Lips-Wiersma and Morris, the idea of expressing full potential relates to competence, creating unity with others to relatedness, and serving others to beneficence. However, the category of developing and becoming self does not, as such, fit into the frame of self-determination theory, even though being able to stay true to oneself requires autonomy, that is, one of the psychological needs according to SDT. Instead, Rosso et al. (2010) and Chalofsky (2003) include autonomy more explicitly in their theorizations of meaningful work, also presented above, and thus regard it as an essential element in experiencing the work as meaningful.

In this article, we utilize especially the theorization of Martela and Riekki since, unlike many other theorizations of meaningful work, it has been empirically tested (Martela and Riekki 2018, p. 2). It also offers clear and distinct categories for the sources of meaningful work which can be easily used in the analysis of our data.

\section{Meaningful Work in All Shades of Collars}

Blue-collar occupations are typically characterized by a relatively low skill level, lower education, and a lower degree of complexity, and also by manual instead of nonmanual labor (Kerbo 1996, see also Torlina 2011). According to Torlina (2011, p. 23), there is a "common and long-standing assumption about manual labor-that it has little intrinsic value for workers beyond the paycheck it provides." However, blue-collar workers themselves may value their work highly (Torlina 2011) and perceive that dignity is based on the quality of the job accomplished and not the status of the job (Lucas 2001).

This study concentrates on the meaningfulness of blue-collar work, which is not so often studied. However, according to research, cleaning (Wrzesniewski and Dutton 2001), catering (Isaksen 2000), and dirty work (Kreiner et al. 2006) provided considerable meaning for some blue-collar workers. These studies have mainly focused on individual aspects of meaningfulness in blue-collar work, such as individual job crafting (Wrzesniewski and Dutton 2001), identity work (Kreiner et al. 2006) and the individual construction of meaningfulness in work (Isaksen 2000). Our study extends the research on meaningfulness of work by scrutinizing the influence of the contexts and preconditions of work on the sources of meaningful work for blue-collar workers.

Additionally, there are some comparisons between the meaningfulness of manual work and knowledge work. In a study using the Comprehensive Meaningful Work Scale (LipsWiersma and Wright 2012), it was found that blue-collar workers attached less importance to expressing their full potential and serving others than white-collar workers. However, unity with others and developing the inner self were regarded as equally important for white-, blue-, and, pink-collar workers (Lips-Wiersma et al. 2016). Additionally, people in higher positions in the organizational hierarchy experience more meaningfulness in work. One explanation could be that those in higher positions in an organization usually also have more autonomy as regards their work than do those in lower positions (Martela and Riekki 2018). 
González et al. (2016) compared the degree to which satisfaction of basic psychological needs for autonomy, relatedness, and competence explained the association with socioeconomic status. Socioeconomic status groups were composed according to education, personal wages, and occupational rank: executive, supervisory, clerical/skilled non-manual, and manual workers. The study revealed individuals with lower socioeconomic status having lower satisfaction of their basic psychological needs than with their counterparts with higher socioeconomic status.

Finland, like the other Nordic countries, stands out from the rest of the Europe in terms of job quality: employees' opportunities to influence their work and use and develop skills are high and the risk of class polarization is low as inequalities in job quality have decreased between manual and professional employees (Mustosmäki 2017). Despite the high level of job quality in Finland overall, manual work has its own challenges and risks According to the Finnish Working Life Barometer 2020, the experienced physical workload of blue-collar workers was considerably higher than in other employee groups, i.e., senior officials and clerical workers. As many as 70 per cent of blue-collar workers felt that their work was physically burdensome, and the share has increased over the last 20 years. Blue-collar workers also reported more combined physical and mental burden than other employees and they had lower scores on experienced physical working ability. They were moreover less able to develop working practices and exert influence at the workplace and less satisfied with the learning opportunities in work (Ministry of Economic Affairs and Employment of Finland 2021).

\section{Research Design and Methods}

Our research data consisted of responses to one open-ended question in a survey on professional pride and meaningfulness of work and 29 semi-structured interviews with blue-collar workers from property services and the manufacturing industry in Finland. The respondents were contacted through labor unions and thus all the respondents were union members. We conducted a web survey in spring 2020 and altogether 1242 respondents completed the survey (see Table 1).

Table 1. Survey data.

\begin{tabular}{|c|c|c|c|}
\hline & Manufacturing $(N=662)$ & Property Services $(N=580)$ & Total $(N=1242)$ \\
\hline \multicolumn{4}{|l|}{ Gender } \\
\hline Woman & $30 \%$ & $64 \%$ & $52 \%$ \\
\hline Man & $67 \%$ & $35 \%$ & $46 \%$ \\
\hline Other/declines to report & $2 \%$ & $1 \%$ & $2 \%$ \\
\hline Age, mean, in years & 45 & 46 & 45 \\
\hline \multicolumn{4}{|l|}{ Employment contract } \\
\hline Permanent (full or part time) & $85 \%$ & $86 \%$ & $85 \%$ \\
\hline Fixed term & $3 \%$ & $6 \%$ & $5 \%$ \\
\hline Other & $12 \%$ & $8 \%$ & $10 \%$ \\
\hline Agency work & $5 \%$ & $8 \%$ & $6 \%$ \\
\hline
\end{tabular}

The survey included an open-ended question "What makes your work meaningful for you?" and there were altogether 679 responses to this question in the respondents' own words. In the property services, 226 women and 120 men responded. In the manufacturing industries, 120 women and 214 men responded. In our analysis, we used both interviews and the responses to the open-ended question mentioned above. The open-ended responses afforded us an understanding of the variety of issues that support employees in their work, whereas the interviews made it possible to better understand the circumstances and contextual issues making work meaningful.

We offered the survey respondents an opportunity to volunteer for interview and the interviewees were selected from among the volunteers. There were seven main themes in the interview: current work and work history; demands, expectations, and duties of 
work; supervision/management; professional pride and meaningfulness of work; pay and remuneration; work during COVID-19 and, finally, future plans for work. We interviewed a total of 29 respondents: 15 from the property services field and 14 from the manufacturing industry. All interviews, except one, were conducted by telephone due to the restrictions caused by the pandemic. The property services interviews also included one interview which resulted from directly contacting organizations and was conducted face-to-face before the restrictions came into force. The interviews lasted from 20 to $75 \mathrm{~min}$. The semi-structured interviews were recorded and later transcribed verbatim by an outsourced professional firm. All interviewees had permanent contracts, except one who had a fixedterm, zero-hour contract. Some other details of the interviewees are given in Table 2.

Table 2. Interview data.

\begin{tabular}{lcc}
\hline & Manufacturing $(N=\mathbf{1 4})$ & Property Services $(\boldsymbol{N}=\mathbf{1 5})$ \\
\hline Gender & 8 & 11 \\
Woman & 6 & 4 \\
Man & & 46 \\
Age & 45 & $35-62$ \\
Mean, in years & $24-63$ & 2 \\
Range & & 3 \\
Work years in current & & 4 \\
organization & 1 & 6 \\
Less than a year & 5 & 2 \\
1-5 years & 2 & \\
6-10 years & 6 & \\
Over ten years & & \\
\hline
\end{tabular}

The present study takes a deductive, theory-led approach and the chosen analytical tool was content analysis. Qualitative content analysis entails both close reading of the data and interpretation affected by the researcher's cultural understandings and the context of the analysis (Krippendorff 2014). The analysis is theory led (on deductive theoretical design see (Patton 2015)) as we are focused on finding expressions of meaningfulness in work and especially how satisfying the four psychological needs included in self-determination theory (Ryan and Deci 2000, 2017; Martela and Riekki 2018) is articulated in the data. Thus, the aim of the analysis is not to measure how meaningful the workers perceive their jobs to be, but to highlight and analyze the descriptions in which the basic psychological needs appear to be fulfilled at work. The aim of the analysis is rather to utilize the theorizations of meaningfulness in work to ascertain if they resonate in the expressions of the bluecollar workers.

The responses to the open-ended question were first coded freely and those coded responses were then reread together with the other responses in the same category and linked-where applicable - to the four sources of meaningfulness central in this study: autonomy (e.g., independence, freedom), competence (e.g., know-how, challenging work, visible results, problem solving), relatedness (e.g., social aspects), and beneficence (e.g., helping). The division between categories is not always clearcut since categories often overlap and are connected simultaneously to several sources of meaningfulness.

The interview data were first read throughout, not merely focusing on specific questions about meaningfulness. It was often difficult for the interviewees to directly describe why their work was meaningful for them, but the series of questions pertaining to issues, such as feelings of appreciation and pride, evaluation of supervisory work, and on favorite work tasks helped to elucidate the important issues. Interview questions concerned both the positive and negative sides of work. A summary was first made of each interview. Each summary included descriptions of the interviewees' work and its requirements, and the main points and relevant quotations emerging in the interview relating to the four sources of meaningfulness. Relevant content was then assigned to each category representing a source of meaningfulness. At the next stage, negative aspects were filtered out of the 
analysis and the focus was placed on how each source of meaningfulness was positively realized in work.

Interviews and responses to open-ended questions are different kinds of data: the interview format elicited much more detailed responses that also revealed problems and difficulties, the troublesome conditions and contexts of work. Responses to open-ended questions were more direct and brief descriptions, with sometimes only one word (such as 'pay') in response. With the interview data, it was easier to understand how the specific response came about and what specifically was meant by it. Therefore, the interview data are central to our qualitative analysis although both data were used in the process.

\section{Results}

\subsection{Autonomy}

Autonomy - as in enjoying taking responsibility, exerting influence in the work organization and coping without supervisory control—was the most common issue raised by the blue-collar workers in our data. Autonomy was typically described as independence or freedom at work, although with preconditions and restrictions. For example, employees compared their work to that of their peers and to the image of work in the manufacturing industry. Thus, independence and freedom were relative, context bound and normative: when one does one's job, one can be free, for example, to be able to influence on one's work schedule.

Different work processes framed the appearance of autonomy: in manufacturing work, autonomy could be about negotiating one's daily schedules without being dependent upon the machinery in the factory and having opportunities to exert influence over one's work. Although manufacturers carried out partitioned work on production line, they also saw themselves as independent workers who were responsible for their part of the job:

I am fascinated by the independence and physicality of the work, since I am mainly solely responsible for the results of my work. Of course, other production departments affect my work but I operate my machine alone. (woman, manufacturing)

Self-determination was thus possible in the production process, even with the awareness of the larger frame and connections to other parts of the process. In turn, for women working in property services-mostly as cleaners-autonomy, in practice, meant being able to determine the order of their own work tasks, also what to do and how to do it. In property services, work autonomy was very much linked to the cleaning practices and work order:

I am able to influence [organizing work] quite a lot. [..] For example, in what order we do things. And since we have work instructions, meaning that some targets are cleaned only three times a week, I can decide on which days we clean them. So there are no specific days for them but I can modify [the schedule]. (woman, property services)

Autonomy was also defined by the quality of supervisor-employee relationships. The following example raises trust and organizational practices as supportive of autonomy, which also made it possible to work without constant surveillance by supervisors:

The employer doesn't come to stand over you to see if you are doing [your job]. In the performance appraisal we talked about it, that there's no surveillance. The employer only said that we have their trust that we are trusted to do our jobs, so there's no need to come and see. (woman, manufacturing)

At best, organizational supervisory practices such as performance appraisal could serve as channels for feedback and normalize the independence of work. Indeed, practices of delegation in the workplace may be conducive to autonomy. Additionally, the following example highlights how the organizing work at the workplace improved the workers' opportunities to act autonomously. However, there were clear instructions on the bounds of self-determination and responsibilities. Some work typically within the supervisor's realm had been delegated to employees to negotiate with each other or decide how to operate when problems with machinery emerged: 
[T] The personnel can change shifts amongst ourselves so that we need only to notify the boss that we've changed shifts. [..] Nowadays our machines have been categorized by importance so that No. One has to run unless it's out of order and No. Twos when they start to act up, then you are allowed to shut them down if you can't fix them on an evening or night shift. (woman, manufacturing)

The independent aspects of work were also made possible by peer negotiation and support: in cleaning, work could be planned and followed through together with a colleague without any official hierarchy or supervision. Often, the workers did not even meet their superiors daily. However, the lack of supervision also meant that cleaners had to negotiate with clients themselves and tackle the frequently tight work schedules. In daily work, cleaners became their own supervisors:

It's become a habit to set a goal for each workday to get through tightly scheduled work with quality. I can forgive myself if I don't always succeed. (woman, property services)

In this data extract, setting one's own goals gave the opportunity to be flexible about the results, knowing the context and frames created by the limited time available for work. All in all, autonomy was expressed as ways of making room for self-determination made possible by supportive organizational practices, low hierarchies, and trust but also by the necessity to self-manage work when there were few other options.

\subsection{Competence}

Competence contributed positively to the meaningfulness of work in at least three ways: firstly, realizing one's own competencies, secondly, gaining recognition for one's competences and thirdly, adapting to the demands of work. Competence entailed occupational skills: knowing what to do and how and mastering one's work environment and its requirements. Meaningfulness emerged from the use of and opportunity to develop occupational skills, continuous, daily use of competencies, understanding how one's work is connected to the larger whole of production.

Realizing one's own competencies could happen while engaged in the practices of work. Everyday work may reveal one's potential and support a view of oneself as an able and competent worker:

It is also nice to notice that I generally have potential for working life as a whole: I've noticed I'm much more competent in many things than I thought before. (woman, manufacturing)

Thus, work itself could be a key to unlocking competencies and supporting meaningfulness. Employees made their skills and the demands of blue-collar work visible in many ways. Gaining recognition for competencies-also from outside one's own workplace-was partly about confronting stereotypes: the image of blue-collar work and the actual content did not match, and indeed manual work may be complex and demand broad expertise:

Our branch is such that not many know what we actually do there. Many think that we just go there and work on the production line, but it isn't like that. After all, we have to have quite extensive know-how, because we have these robots and such. But many people think that we just go there and put things in a box. (man, manufacturing)

To find the work challenging was often important for meaningfulness. Positively charged meanings of challenging work included the novelty and regularity of challenges: challenges were something to overcome and they were important in counterbalancing the more routine aspects of work. Problem solving was a chance to use and develop one's competencies:

The feeling you get when you finally get the fault fixed after many hours of work. (man, property services)

In cleaning work, competence was tangible. Both in the interviews and especially in the open-ended responses in the survey, the visibility of the work of one's own hands was mentioned as bringing meaningfulness to work, as in the following example: 
In such moments when you notice that, this was a success [..] even in those times when you went to an awful kitchen and when you left it, you would look behind you that it was shining and sparkling clean, indeed then came this wow, I did it. (woman, property services)

Being content with one's work and its results was also expressed by the manufacturers, who saw themselves as competent at manufacturing quality products. Verbal praise and positive feedback made their competence visible:

I: [I see I am appreciated] at least when they [the supervisors] sometimes come to thank me. That now things have gone well. That there haven't been any mistakes and such, then indeed you notice that you're appreciated. (man, manufacturing)

Getting good feedback was a sign of appreciation for one's competence. However, feedback from supervisors was rare and in the case of cleaners, clients' feedback was an important source of praise:

I'm able to utilize my training and experience and every now and then a colleague happily takes tips from me. I get satisfaction from seeing the results of my work. I'm used to that when everything's fine, there's not a word, but if a grain of rice is found by a baseboard on an otherwise clean floor, there's an instant complaint. I am happy that I can bear this system. (woman, property services)

The previous extract from property services discusses how to handle the lack of positive feedback and brings together many other aspects of meaningfulness discussed in this sub-section: the use of skills and tangible outcomes of work. Yet, it also shows how the ability also to adapt to and endure the challenging or negative aspects of work required competence born of experience. In addition to these, the opportunity to solve problems and tackle challenges was a prominent feature of the meaningfulness of work.

\subsection{Relatedness}

The analysis of relatedness centered around peer relationships, flat hierarchies, and client relations. Social relationships were important for meaningfulness and were realized in different kinds of arrangements.

A good work community may diminish the negative sides of work, as shown in the following data extract. Firstly, social relationships with peers helped to overcome the experience of doing dirty work and, secondly, brought positive meaning to one's work:

It doesn't really matter what I do as long as working is enjoyable. This enjoyability is usually mostly affected by workmates and the work community in general. If it's nice to go to work and you have fun there, then it doesn't matter if the work is cleaning up vomit. (woman, property services)

In factory work, team effort was a more prominent feature of work than in property services. The sociability as well as the work performance could be tied to team members in a way that also served to alleviate stress:

[W]ith workmates we have a good spirit and team work in this position suits me-one good side e.g., that for a type like me who's prone to stress, responsibility for quality is shared between many people. (man, manufacturing)

Care was also introduced as an aspect of peer relationships. This next extract highlights the methods and importance of relatedness and how workmates are included in a circle of care among cleaning professionals:

We've had the same crew for a long time and generally, if somebody doesn't come to their break, for example, because of taking a packed lunch to the [cleaning] location, if that person doesn't let us know she's not coming, then we usually call that person and ask if everything's OK, when they don't show. It's a bit of looking after people. (woman, property services) 
Workers tried to find ways to interconnect even though their work schedules or other conditions limited their social interaction. Taking time to share social space also stressed the importance of relatedness and the tightness of schedules in cleaning work:

We have the habit that when the working day begins at six, we are at the workplace at half past five because we want to chat a little in the morning without any hurry. We always have a chat there and then go to work. It's the workmates. It's pretty much, if they are good, then you can go on. (woman, property services)

Flat hierarchies of the social relationships at the workplace increased the sense of togetherness. Cleaners' work is, according to the interviewees, often undervalued by the employees of the client organization and cleaners are not necessarily seen as members of the work community. Those cleaners who had good relationships in their workplace, highly appreciated it:

[In my former job] there is a really hierarchical system, but for example here, even though we have a supervisor, have higher and lower [positions], you know, we sit in the same coffee room. And we're on the same line. (woman, property services)

Manufacturers also highlighted the importance of communality in the workplace. Positive experiences of lowering organizational hierarchies increased the sense of working for a common goal. Team spirit could include not only peers but also supervisors. Bluecollar workers saw themselves as important members of the organization, "not as replaceable tools", as one interviewee described it.

It was not possible in all kinds of work to experience relatedness to one's peers. For example, cleaners who often worked at different client locations could be more isolated from their own work organization, but social relationships were still quite important for them, too, to experience meaningfulness. In that case, the significance of client relationships was more prominent than in other kinds of blue-collar work in contributing to the meaningfulness of work.

At best, meaningfulness could be drawn from the whole range of possible social relationships that also ensured appreciation:

There's a good community spirit in our team and I also get appreciation from workmates as well as from supervisors and our clients. (woman, property services)

Relatedness seemed to play an important role in the meaningfulness of blue-collar work. Even when the work itself is not so interesting, a good work community can compensate for this and make work meaningful. Equality and experience of being valued members of the organization are important for blue-collar workers: in this sense, relatedness entails that they are appreciated not only by their co-workers but also by their clients (in property service work) and by their superiors. Employees are prepared to make an effort to retain the social relationships they deem important.

\subsection{Beneficence}

Beneficence emerged in our data as helping peers and those directly benefiting from one's work but also as contributing to society at large. Blue-collar workers found meaningfulness in their work by helping those around them, those who use the products they make or use the premises they take care of, and finally, the whole society.

Helping peers was an easily accessible resource for experiencing meaningfulness in work. For example, the multicultural nature of the work community in cleaning offered opportunities not only for varying social contacts but also to help others:

Our work community has people from pretty many different cultures, which has been good or interesting. There are Africans and Russians and from Vietnam. That's nice. It feels like you couldn't be in this work if you're somehow racist or something. [..] They don't all necessarily for example read Finnish well, so one person has asked me, too, to help with a paper which is kinda nice. (man, property services) 
The next level of beneficence offered fulfillment in providing services that resulted in expressly satisfied clients or in seeing to their healthy environment (e.g., in the case of cleaning hospitals or laboratories):

[Cleaning] is the basis for everything [..] if you think about hospitals. [..] In hospitals it's indeed a safety issue, and elsewhere too. (woman, property services)

The work was not just cleaning the floors, but also helping patients and offering care. Providing for others was recognized as an important part of the work as in the case of a worker in property services who said "my main agenda is to make things possible for others".

Although manufacturing work provided fewer opportunities to be in contact with clients, the end product could be something important for its users and workers could also see their work as something that truly helped people. One manufacturer summed it up by saying "I know how important the product is".

Awareness of the product and the part one played in the work process helped to find meaningfulness in work. Contributing to the safety and security of the users of the product also gave meaningfulness, for instance, to this man working in manufacturing:

Well, it's of course nice to do those tests that promote safety and maintaining safety [..]

I happen to be one link in the chain there who's physically there [to do the job]. But of course, I have my finger in the pie as well. You have to be proud yourself and praise yourself every once in a while. (man, manufacturing)

Not only recognizing one's place and importance in the work process, but also being a part of an even larger whole globally could be a source of meaningfulness:

I feel what I do is an important part of the process, and me as a worker I am part of a global community. (man, manufacturing)

As is also indicated in the previous example, beneficence could be recognized on several levels simultaneously:

The chance to help others to do a good job means a lot. To contribute to society as well as the immediate surroundings. (man, manufacturing)

Thus, beneficence in one's work did not only appear as contact and care between peers or as service or products provided for users, but also as perceiving work as part of a wider context, the whole society. In this following data extract, a man working in maintenance drew a bigger picture of the importance of work as an inseparable part of maintaining the Finnish infrastructure:

Property services are among those branches that are good in that you can't unscrew this equipment and take it to China, so [the work] has to be done here on location. A very large part of our national property is attached to real estate here in Finland ... and somebody has to take care of that property. (man, property services)

Although cleaning work could in many ways be rendered invisible, the understanding that good cleaning is the basis for other activities brought a sense of contributing to society at large. Cleaners saw their work as meaningful because "without it, Finland would not function". In manufacturing work, the meaningfulness of work is also seen through its meaning for society: "I get to work [in Company X] and help society because the export industry is an important branch; I do my part in the running of society".

Beneficence was an element of meaningfulness in blue-collar work that stressed the importance of the efforts of the workers. Thus, helping clients, co-workers, the organization, and the whole society made their work meaningful. Recognizing the connections and effects of work made beneficence an available source for experiencing meaningfulness.

\section{Discussion}

In this article, we were interested in how the meaningfulness of work-as in autonomy, competence, relatedness, and beneficence-is articulated by people in blue-collar occupations in property services and manufacturing. Our results reveal that satisfying the four basic psychological needs can be a source of meaningfulness in blue-collar work. Workers 
felt that their work was autonomous, and they often worked without supervision and made decisions alone. In addition, they reported that their work required diverse competence, and realizing one's own competence makes work meaningful. Relatedness in blue-collar work is about having good relations with co-workers and the employees interviewed were ready to strive to maintain those relationships. Beneficence was recognized as important on several levels: helping clients, co-workers, the employer organization and society as a whole.

The analysis of the forms of autonomy indicated that while there are limitations and restrictions to the degree of choice in blue-collar work, it is not so closely monitored (see Torlina 2011) as to offer no experiences of autonomy. In fact, there can be a lot of self-management to the point that employees reported that they did not actually need supervision in their daily work. Supervisors can be a rare sight on the factory floor or in cleaning work, where the work is typically done on clients' premises. At best, the relationship between supervisors and employees was described as being based on trust, which made close surveillance unnecessary. Employees also created their own selfmanagement practices to organize their working days and to create a sense of achievement. Autonomy in blue-collar work means options to choose even in restricted conditions. All in all, the analysis highlighted the importance of creating circumstances for experiencing autonomy.

The analysis of competence showed the multitude of ways in which the work made realizing and recognizing competencies possible: not only in utilizing professional training but also in learning the nature and conditions of work and how to manage them. This management work included adjusting to the demands of work and how to cope with them. Blue-collar occupations are often thought of as undemanding in respect to skills, education, and complexity (Kerbo 1996; Torlina 2011); but in this study, the informants made the complexities and demands of their work visible: boundaries between blue-collar and other kind of work were stretched or broken, for example, by increased technical requirements, robotization, and the need for social skills as part of the work. The quality of the job performance (as suggested by Torlina 2011) proved to be important: the tangible results of work were often mentioned as bringing satisfaction and pride. Problem solving balanced the routines and monotonous sides of work.

In addition to competence, relatedness was also key in tackling the sometimes monotonous sides of work. If the work itself is not so interesting, a good work community can make work meaningful. Flat hierarchies supported both relatedness and the sense of working towards a common goal. Social relationships supported seeing the value of one's work and sharing the workload with trusted colleagues made coping with work easier. The findings indicate that opportunities for social connections should be supported in as many ways as possible: employees made space for social relationships even in challenging working conditions, tackling such troubles as distance and lack of time.

Beneficence was linked to meaningfulness of work on three levels: by helping the clients or the users of the products (or the premises that are taken care of), helping coworkers or the organization and finally, helping the whole society. Both in property services and in manufacturing, the employees understood themselves as a part of a larger whole to which they contributed. This finding suggests that beneficence cannot be disregarded as a source of meaningfulness even in blue-collar work.

In our analysis we found that all psychological needs played a part in the experiences of meaningful work recounted by the blue-collar workers. Consequently, beneficence, the fourth basic psychological need proposed by Martela and Riekki (2018) was also addressed as a source of meaningfulness in blue-collar work. Growth orientation, which is seen as characteristic of meaningfulness of work (Steger et al. 2012), became apparent especially in the competence category of our analysis, for instance, as learning new occupational skills. It also emerged as autonomy, as becoming more and more independent in performing the job. Purpose orientation, also regarded as an essential feature of meaningfulness (Steger et al. 2012), manifested especially in beneficence; the workers understood their 
input to a larger system. However, the purpose orientation also emerged in relatedness as the work community fostered the sense of purpose in the work. Our approach differs from that of earlier studies in this respect: instead of stressing the individual, personal perspective, we addressed meaningfulness sociologically, taking into account the contexts and preconditions in which meaningfulness is created, managed, and to which it is bound. Our study reveals that the preconditions for meaningfulness in blue-collar work are strictly tied to the organization of work. Even though workers have autonomy to a certain extent, they can not develop or modify their work in the same way as knowledge workers can (see also Lips-Wiersma et al. 2016). In addition, we aimed to contribute to the discussion about the theory on the meaningfulness of work and beneficence as an addition to the theory. In this article, we found that beneficence is also relevant for meaningfulness in bluecollar work. Thus, we believe that beneficence should be studied further in other forms of blue-collar work to ascertain to what extent different types of work offer opportunities for beneficence.

Although the theory of basic psychological needs provides an excellent frame for analyzing meaningfulness, it omits one important aspect of blue-collar work: the necessity of work as source of livelihood and income. Especially in the industrial field, workers say that they are "working just to make money". In addition, some say that it is important to have a job at all. Such responses refer to an idea of work as a pure necessity.

Although we found that satisfying the four basic psychological needs can be a source of meaningfulness in blue-collar work, we do not claim that the basic psychological needs are always fulfilled. Indeed, when talking about what is important in their work, people often talked about the problems they had had and how they had overcome them. This was more noticeable in interviews than in the data answering open-ended questions. However, by showing that blue-collar work provides opportunities for experiencing meaningfulness, we want to draw attention to it as both valuable work and as work with good foundations for further improvement.

This article aimed to consider the contribution of qualitative data in researching meaningfulness in work. Our informants showed through their accounts how subjective experiences are articulated in particular personal and organizational conditions. Qualitative analysis showed that the contexts influenced the ways in which the sources of meaningfulness could manifest and how employees made use of organizational practices in making their work meaningful.

In light of the findings of this study, we suggest that supervisors should also enhance meaningfulness, both in their own work and help employees to find meaningfulness in their work. For example, they could strive to ameliorate the working conditions and professional development of their employees, to create positive and significant relationships with their employees, and to set clear and coherent objectives (Frémeaux and Pavageau 2020). Supervisors could also express trust in competent employees by giving them responsibility and opportunities to exert influence in order to enhance their sense of autonomy.

Based on the results of this study, we suggest that organizations should develop organizational practices that may enhance meaningfulness in work, such as opportunities to use and develop occupational skills. Finland suffers from a shortage of skilled labor in both the industries studied in this article. Therefore, to ensure a better commitment to the organization, it is important to enhance employee well-being on every level and to invest effort in enabling the prerequisites for meaningfulness.

Regarding future avenues of research, the first stages of analysis revealed a wide range of themes with potential for ascertaining what is important for people in their work. Firstly, analyzing affect and affective elements in the qualitative data could help identify underlying issues related to the problems and rewards of blue-collar work. Secondly, there are interesting connections between different sources of meaningfulness that enable and challenge each other. Further study of such connections could support creating opportunities to experience work as meaningful and help identify and solve contradictions between them in blue-collar work. 


\begin{abstract}
Author Contributions: Conceptualization, T.S., M.L. and K.T.; methodology, T.S., M.L. and K.T.; software, T.S. and M.L.; validation, T.S., M.L. and K.T.; formal analysis, M.L. and T.S.; investigation, T.S., M.L. and K.T.; resources, T.S., M.L. and K.T.; data curation, T.S. and M.L.; writing-original draft preparation, T.S., M.L. and K.T.; visualization, T.S.; supervision, T.S.; project administration, T.S.; funding acquisition, T.S. All authors have read and agreed to the published version of the manuscript.

Funding: This research was funded by Finnish Work Environment Fund, grant number 190160. The APC was funded by Tampere University.

\section{Institutional Review Board Statement: Not applicable.}

Informed Consent Statement: Informed consent was obtained from all subjects involved in the study.

Data Availability Statement: The data will be later on made publicly available at the Finnish Social Science Data Archive.

Conflicts of Interest: The authors declare no conflict of interest. The funders had no role in the design of the study; in the collection, analyses, or interpretation of data; in the writing of the manuscript, or in the decision to publish the results.
\end{abstract}

\title{
References
}

Allan, Blake A., Kelsey L. Autin, and Ryan D. Duffy. 2016. Self-Determination and Meaningful Work: Exploring Socioeconomic Constraints. Frontiers of Psychology 7: 71. [CrossRef]

Autin, Kelsey L., and Blake A. Allan. 2020. Socioeconomic Privilege and Meaningful Work: A Psychology of Working Perspective. Journal of Career Assessment 28: 241-56. [CrossRef]

Both-Nwabuwe, Jitske M. C., Maria T. M. Dijkstra, and Bianca B. Beersma. 2017. Sweeping the Floor or Putting a Man on the Moon: How to Define and Measure Meaningful Work. Frontiers of Psychology 8: 1658. [CrossRef]

Bunderson, J. Stuart, and Jeffery A. Thompson. 2009. The Call of the Wild: Zookeepers, Callings and the Double-edged Sword of Deeply Meaningful Work. Administrative Science Quarterly 54: 32-57. [CrossRef]

Chalofsky, Neal. 2003. An Emerging Construct for Meaningful Work. Human Resource Development International 6: 69-83. [CrossRef]

Deci, Edward L., and Richard M. Ryan. 2000. The "What" and "Why" of Goal Pursuits: Human Needs and the Self-determination of Behavior. Psychological Inquiry 11: 227-68. [CrossRef]

Deci, Edward L., Richard M. Ryan, and Richard Koestner. 1999. A Meta-analytic Review of Experiments Examining the Effects of Extrinsic Rewards on Intrinsic Motivation. Psychological Bulletin 125: 627-68. [CrossRef]

Eurofound. 2017. Occupational Change and Wage Inequality: European Jobs Monitor 2017. Luxembourg: Publications Office of the European Union.

Frémeaux, Sandrine, and Benjamin Pavageau. 2020. Meaningful Leadership: How Can Leaders Contribute to Meaningful Work? Journal of Management Inquiry 31: 54-66. [CrossRef]

González, Maynor G., Dena P. Swanson, Martin Lynch, and Geoffrey C. Williams. 2016. Testing Satisfaction of Basic Psychological Needs as a Mediator of the Relationship between Socioeconomic Status and Physical and Mental Health. Journal of Health Psychology 21: 972-82. [CrossRef]

Hackman, J. Richard, and Greg R. Oldham. 1976. Motivation Through the Design of Work: Test of a Theory. Organizational Behavior and Human Performance 16: 250-79. [CrossRef]

Isaksen, Jesper. 2000. Constructing Meaning Despite the Drudgery of Repetitive Work. Journal of Humanistic Psychology 40: 84-107. [CrossRef]

Kerbo, Harold R. 1996. Social Stratification and Inequality: Class Conflict in Historical and Comparative Perspective, 3rd ed. New York: McGraw-Hill.

Kreiner, Glenn E., Blake E. Ashforth, and David M. Sluss. 2006. Identity Dynamics in Occupational Dirty Work: Integrating Social Identity and System Justification Perspectives. Organization Science 17: 619-36. [CrossRef]

Krippendorff, Klaus. 2014. Content Analysis. An Introduction to Its Methodology, 3rd ed. Los Angeles, London, New Delhi, Singapore and Washington, DC: Sage.

Lips-Wiersma, Marjolein, and Lani Morris. 2009. Discriminating Between Meaningful Work and the Management of Meaning. Journal of Business Ethics 88: 491-511. [CrossRef]

Lips-Wiersma, Marjolein, and Sarah Wright. 2012. Measuring the Meaning of Meaningful Work: Development and Validation of the Comprehensive Meaningful Work Scale (CMWS). Group \& Organization Management 37: 655-85. [CrossRef]

Lips-Wiersma, Marjolein, Sarah Wright, and Bryan Dik. 2016. Meaningful Work: Differences among Blue-, Pink-, and White-collar Occupations. Career Development International 21: 534-51. [CrossRef]

Lucas, Kristen. 2001. Blue-Collar Discourses of Workplace Dignity: Using Outgroup Comparisons to Construct Positive Identities. Management Communication Quarterly 25: 353-74. [CrossRef]

Martela, Frank, and Tapani J. J. Riekki. 2018. Autonomy, Competence, Relatedness, and Beneficence: A Multicultural Comparison of the Four Pathways to Meaningful Work. Frontiers of Psychology 9: 1157. [CrossRef] 
Milligan, William R., Zachary L. Fuller, Ipsita Agarwal, Michael B. Eisen, Molly Przeworski, and Guy Sella. 2021. Impact of essential workers in the context of social distancing for epidemic control. PLoS ONE 16: e0255680. [CrossRef]

Ministry of Economic Affairs and Employment of Finland. 2021. Working Life Barometer 2020. Available online: https://julkaisut. valtioneuvosto.fi/handle/10024/163200 (accessed on 24 June 2021).

Mustosmäki, Armi. 2017. How Bright Are the Nordic Lights? Job Quality Trends in Nordic Countries in a Comparative Perspective. Jyväskylä Studies in Education, Psychology and Social Research 586. Jyväskylä: University of Jyväskylä.

Nikolova, Milena, and Femke Cnossen. 2020. What Makes Work Meaningful and Why Economists Should Care About It. Labour Economics 65: 101847. [CrossRef]

Patton, Michael Quinn. 2015. Qualitative Research and Evaluation Methods: Integrating Theory and Practice, 4th ed. Los Angeles, London, New Delhi, Singapore and Washington, DC: Sage.

Pratt, Michael G., and Blake E. Ashforth. 2003. Fostering Meaningfulness in Working and at Work. In Positive Organizational Scholarship. Edited by Kim Cameron, Jane Dutton and Robert E. Quinn. San Francisco: Berret-Koehler Publishers, pp. 309-27.

Rosso, Brent D., Kathryn H. Dekas, and Amy Wrzesniewski. 2010. On the Meaning of Work: A Theoretical Integration and Review. Research in Organizational Behavior 30: 91-127. [CrossRef]

Ryan, Richard M., and Edward L. Deci. 2000. Self-determination Theory and the Facilitation of Intrinsic Motivation, Social development, and Well-being. American Psychologist 55: 68-78. [CrossRef] [PubMed]

Ryan, Richard M., and Edward L. Deci. 2017. Self-Determination Theory: Basic Psychological Needs in Motivation, Development, and Wellness. New York: Guilford Press.

Scarduzio, Jennifer A., Kevin Real, Amanda Slone, and Zachary Henning. 2018. Vocational Anticipatory Socialization, SelfDetermination Theory, and Meaningful Work: Parents' and Children's Recollection of Memorable Messages About Work. Management Communication Quarterly 32: 431-61. [CrossRef]

Secrest, Janet, Daniel H. Iorio, and Wallis Martz. 2005. The Meaning of Work for Nursing Assistants Who Stay in Long-term Care. Journal of Clinical Nursing 14: 90-97. [CrossRef] [PubMed]

Statistics Finland. 2021. StatFin Database 2021. Available online: https:/ / beta.stat.fi/en/database-tables (accessed on 29 November 2021).

Steger, Michael F., Bryan J. Dik, and Ryan D. Duffy. 2012. Measuring Meaningful Work: The Work and Meaning Inventory (WAMI). Journal of Career Assessment 20: 322-37. [CrossRef]

Torlina, Jeff. 2011. Working Class. Challenging Myths About Blue-Collar Labor. Boulder: Lynne Rienner Publishers.

Trougakos, John P., Ivona Hideg, Bonnie Hayden Cheng, and Daniel J. Beal. 2013. Lunch Breaks Unpacked: The Role of Autonomy as a Moderator of Recovery During Lunch. Academy of Management Journal 57: 405-21. [CrossRef]

Van den Broeck, Anja, D. Lance Ferris, Chu-Hsiang Chang, and Cristopher C. Rosen. 2016. A Review of Self-Determination Theory's Basic Psychological Needs at Work. Journal of Management 42: 1195-229. [CrossRef]

Weeks, Kelly Pledger, and Caitlin Schaffert. 2019. Generational Differences in Definitions of Meaningful Work: A Mixed Methods Study. Journal of Business Ethics 156: 1045-61. [CrossRef]

Wrzesniewski, Amy, and Jane E. Dutton. 2001. Crafting a Job: Revisioning Employees as Active Crafters of Their Work. The Academy of Management Review 26: 179-201. [CrossRef]

Yeoman, Ruth. 2014. Conceptualizing Meaningful Work as a Fundamental Human Need. Journal of Business Ethics 125: 235-51. [CrossRef] 